\title{
Efektivitas Sistem Akuntabilitas Kinerja Instansi Pemerintah (SAKIP) pada Dinas Pertanian dan Pangan Kota Magelang
}

\author{
Ricky Mukaromah', Nuwun Priyono² \\ ${ }^{1}$ Akuntansi, fakultas ekonomi, universitas Tidar \\ e-mail : ricky.mukaromah@gmail.com \\ ${ }^{2}$ Akuntansi, fakultas ekonomi, universitas Tidar \\ e-mail : nuwunpriyono@untidar.ac.id
}

\begin{abstract}
The purpose of this study was to determine the effectiveness of the Government Agency Performance Accountability System (SAKIP) and to find out the supporting and inhibiting factors for the implementation of SAKIP's effectiveness in the Dinas Pertanian dan Pangan Kota Magelang. This research use desciptive qualitative approach. Data collection techniques using interviews, observation, and documentation. The results of this study indicate that SAKIP in the Dinas Pertanian dan Pangan Kota Magelang has been running effectively. The implementation of SAKIP in the Dinas Pertanian dan Pangan Kota Magelang has increased every year which can be seen from the level of success of the work programs that have been implemented.
\end{abstract}

Keywords: effectiveness, SAKIP

\begin{abstract}
Abstrak
Tujuan penelitian ini untuk mengetahui efektivitas Sistem Akuntabilitas Kinerja Instansi Pemerintah (SAKIP) dan untuk mengetahui faktor pendukung dan penghambatan penerapan efektivitas SAKIP di Dinas Pertanian dan Pangan Kota Magelang. Penelitian ini menggunakan pendekatan kualitatif deskriptif. Teknik pengumpulan data menggunakan wawancara, observasi, dan dokumentasi. Hasil penelitian ini menunjukkan bahwa SAKIP di Dinas Pertanian dan Pangan Kota Magelang telah berjalan efektif. Pelaksanaan SAKIP di lingkungan Dinas Pertanian dan Pangan Kota Magelang mengalami peningkatan setiap tahunnya yang dapat dilihat dari tingkat keberhasilan program kerja yang telah dilaksanakan.
\end{abstract}

Kata kunci: efektivitas, SAKIP

Ricky Mukaromah - Efektivitas Sistem Akuntabilitas Kinerja Instansi Pemerintah (SAKIP)

Page | 89 pada Dinas Pertanian dan Pangan Kota Magelang 


\section{PENDAHULUAN}

Sistem Akuntabilitas Kinerja Instansi Pemerintah (SAKIP) adalah penerapan manajemen kinerja pada sektor publik yang sejalan serta konsisten dengan penerapan reformasi birokrasi yang berorientasikan pencapaian outcome serta upaya dalam menghasilkan hasil yang lebih baik dari pencapaian sebelumnya. Instansi pemerintah yang mempunyai kewajiban untuk menerapkan SAKIP serta menyampaikan pelaporan yaitu instansi yang berasal dari Pemerintah Pusat dan Pemerintah daerah Kabupaten maupun Kota. Penanggung jawab dalam penyusunan Laporan Akuntabilitas Kinerja Instansi Pemerintah (LAKIP) yaitu pejabat pemerintah yang secara fungsional bertanggung jawab dalam melayani fungsi administrasi pada instansi masing-masing, lalu pimpinan instansi bersama anggota kerja diharuskan untuk mempertanggungjawabkan serta menjelaskan keberhasilan maupun kegagalan tingkat kinerja yang telah dicapai. (Andriani et al., 2015).

Dinas Pertanian dan Pangan atau (DISPERPA) Kota Magelang adalah salah satu instansi pemerintah yang telah menerapkan SAKIP. DISPERPA merupakan salah satu perangkat daerah di Kota Magelang yang kedudukannya berada di bawah dan mempunyai tanggung jawab langsung kepada Walikota Magelang yang mempunyai tugas untuk membantu Walikota dalam melaksanakan urusan pemerintah di bidang pertanian, pangan, perikanan, dan peternakan sebagai kewenangan daerah serta tugas pembantuan yang diberikan pada pemerintah daerah.

Kota Magelang termasuk salah satu kota yang terletak di wilayah Provinsi Jawa Tengah. Kota Magelang terletak di tengah Kabupaten Magelang. Kota Magelang mempunyai luas daerah 16,06 $\mathrm{km}^{2}$ dengan jumlah penduduk Kota Magelang yang diambil menurut Wikipedia pada tahun 2019 sebanyak 130.056 jiwa, dengan jumlah penduduk tersebut tidak termasuk kategori daerah yang padat penduduk, Sehingga kebutuhan pangan dan pertanian pun tidak terlalu banyak seperti kota atau kabupaten lain yang memiliki jumlah penduduk yang lebih padat, namun dalam melaksanakan pembangunan pertanian, peternakan 
serta perikanan masih dikatakan belum cukup. Seperti tingginya konversi dari pertanian ke non pertanian sehingga mengancam ketersediaan lahan untuk kelangsungan penyediaan pangan di Kota magelang, konsumsi pangan masyarakat yang belum bergizi seimbang dan aman, dan belum optimalnya pengembangan dan pemanfaatan pangan lokal jaminan mutu pada pangan.

Adanya penerapan SAKIP pada DISPERPA diharapkan kualitas pangan, pertanian, peternakan, dan perikanan di masyarakat akan semakin membaik, selain menerapkan SAKIP, DISPERPA juga harus melakukan pelaporan akuntabilitas kinerja dan akuntabilitas anggaran pada setiap tahunnya yang dituangkan pada LAKIP. Sehingga dalam mengatasi masalah yang ada bisa diatasi secara Bersama-sama baik dilakukan oleh DISPERPA itu sendiri maupun oleh Walikota yang akan berkoordinasi dengan dinas terkait.

Efektivitas merupakan pengukuran tercapainya target serta tujuan yang sudah ditentukan sebelumnya. Menurut Handayaningrat (1995) efektivitas adalah sebuah pengukuran target yang telah direncanakan sebelumnya sudah tercapai. Semakin besar hasil sasaran yang dicapai maka bisa dikatakan efektif dan efisien. Suatu tindakan yang bermakna mengenai terjadinya suatu dampak atau akibat dan menekankan pada output atau efeknya pada pencapaian tujuan.

\section{METODE PENELITIAN}

Penelitian ini merupakan penelitian dengan pendekatan kualitatif deskriptif. Alasan peneliti menggunakan pendekatan ini karena penelitian ini bertujuan untuk memberikan pemahaman tentang isu yang diteliti serta dapat dimanfaatkan untuk menelusuri topik yang baru atau untuk mempelajari permasalahan yang kompleks (Hennink et al, 2012). Pendekatan ini digunakan untuk mengungkapkan secara mendalam efektivitas Sistem Akuntabilitas Kinerja Instansi Pemerintah (SAKIP) pada Dinas Pertanian dan Pangan (DISPERPA) Kota Magelang.

Teknik pengumpulan data menggunakan teknik wawancara serta dokumentasi. Wawancara dilakukan melalui tanya jawab langsung dengan narasumber yang berhubungan langsung dengan penelitian. Pihak yang 
diwawancarai dalam penelitian ini yaitu Kepala Bagian Program dan Keuangan serta staff atau karyawan Dinas Pertanian dan Pangan, sedangkan dokumen yang digunakan untuk disesuaikan dengan kebutuhan guna membantu menjawab pertanyaan peneliti adalah Laporan Kinerja Instansi Pemerintah (LKJIP) Dinas Pertanian Dan Pangan Kota Magelang dan dokumen yang terkait lainnya.

\section{HASIL DAN PEMBAHASAN}

Lokasi Penelitian berada di Dinas Pertanian dan Pangan (DISPERPA) Kota Magelang berlokasi di Jalan Kartini No 3 Cacaban, Kecamatan Magelang Tengah Kota Magelang, Jawa Tengah. Sebagai salah satu Satuan Kerja Perangkat Daerah (SKPD) Dinas Pertanian dan Pangan Kota Magelang mempunyai tugas dan fungsi yang telah diatur pada Peraturan Daerah Kota Magelang Nomor 3 Tahun 2016 Tentang Pembentukan Dan Susunan Perangkat Daerah. Adapun fungsi dari Dinas Pertanian dan Pangan yaitu Perumusan rencana dan kebijakan dalam bidang pangan, pertanian, peternakan dan perikanan, Pengkoordinasian serta pengarahan dalam penyusunan program, pengelolaan keuangan serta urusan umum dan kepegawaian dinas. Keberadaan DISPERPA Kota Magelang sebagai perangkat Daerah dalam mengemban Misi Walikota Magelang adalah Misi Kedua dan misi ketiga.

Dasar hukum yang memperkuat pelaksanaan SAKIP dan Pelaporan LAKIP di Dinas Pertanian dan Pangan Kota Magelang yaitu Peraturan Presiden Republik Indonesia Nomor 29 Tahun 2014 mengenai Sistem Akuntabilitas Kinerja Instansi Pemerintah yang mengemukan bahwa Akuntabilitas Kinerja merupakan perwujudan dari kewajiban instansi pemerintah dalam pertanggungjawaban suatu keberhasilan/ kegagalan dalam rangka pelaksanaan program serta kegiatan yang diberikan pihak-pihak pemangku kepentingan yang kaitannya dalam pencapaian misi organisasi yang terukur dengan target kinerja yang telah dirumuskan melalui laporan kinerja instansi pemerintah secara periodik.

Adanya peraturan dan undang-undang terbaru sebagai penguat pelaksanaan SAKIP dan pelaporan LAKIP yaitu Peraturan Presiden Nomor 29 Tahun 2014 
Tentang Sistem Akuntabilitas Kinerja Instansi Pemerintah, UU Nomor 5 Tahun 2014 Tentang Kinerja Sebagai Dasar Pemberian Tunjangan Dan Pengembangan Kompensasi dan Permenpan RB Nomor 53 Tahun 2014 Tentang Petunjuk Teknis Perjanjian Kinerja, Pelaporan Kinerja, Dan Tata Cara Reviu Atas Laporan Kinerja Instansi Pemerintah. Pada tahun 2014 peraturan Intruksi Presiden Nomor 7 Tahun 1999 tentang Akuntabilitas Kinerja Instansi Pemerintah (AKIP) yang sebelumnya adalah dasar utama penyelenggara SAKIP Pemerintahan Indonesia dicabut dan idak berlakukan lagi dengan dikeluarkan Peraturan Presiden Nomor 29 Tahun 2014 tentang Sistem Akuntabilititas Kinerja Instansi Pemerintah. Sehingga mulai tahun 2014, sebagai dasar penyelenggaraan SAKIP Pemerintah Indonesia menggunakan Perpres No. 29 Tahun 2014.

LAKIP merupakan suatu laporan kinerja tahunan sebagai wujud dari pertanggungjawaban kinerja suatu instansi kaitannya dalam pencapaian tujuan atau sasaran instansi tersebut (Permenpan RB No. 29 Tahun 2010). Selain itu LAKIP berfungsi sebagai penjelasan secara ringkas mengenai pencapaian kinerja yang tersusun berdasarkan perencanaan kegiatan kerja yang sebelumnya telah ditetapkan untuk pelaksanaan APBN/APBD (Perpres No. 29 Tahun 2014).

Penelitian ini mengacu pada penelitian yang pernah dilakukan oleh Puspasari, 2015 dengan judul "Efektifitas Sistem Akuntabilitas Kinerja Instansi Pemerintah (SAKIP) Dinas Kependudukan dan Pencatatan Sipil Kabupaten Puworejo" Efektivitas diukur menggunakan Pendekatan Tujuan. Pendekatan berdasarkan tujuan menekankan pada pentingnya pencapaian tujuan atau sasaran sebagai kriteria dalam penilaian keefektian. Dalam hal ini yang harus dilaksanakan terlebih dahulu yaitu membuat spesifikasi tujuan yang akan dicapai selanjutnya secara berkala untuk melakukan evaluasi terhadap tingkat ketercapaian tujuan tersebut.

Untuk mengukur Efektivitas SAKIP di Dinas Pertanian dan Pangan (DISPERPA) Kota Magelang perlu melihat bagaimana pelaksanaan SAKIP tersebut. Jika SAKIP tersebut berjalan sesuai dengan tujuan dibuatnya SAKIP maka dapat dikatakan SAKIP telah berjalan dengan efektif di Dinas Pertanian dan Pangan. 
Namun jika setelah dilaksanakan kegiatan atau program kebijakan publik ternyata hasil yang didapat tidak mampu untuk memecahkan masalahan di masyarakat, maka kebijakan tersebut dikatakan tidak berhasil dalam pelaksanaannya, namun kadang kala dampak suatu kebijakan publik tidak diperoleh secara efektif dalam waktu jangka pendek melainkan dampaknya diperoleh setelah melakukan proses tertentu.

Untuk mengukur efektivitas dalam penelitian tentang efektivitas Sistem Akuntabilitas Kinerja Instansi Pemerintah (SAKIP) di Dinas Pertanian dan Pangan Kota Magelang peneliti mengukur berdasarkan tujuan (Puspasari, 2015). Menurut Pedoman SAKIP LAN tahun 2010 Tujuan SAKIP adalah :

1. Sarana atau instrumen yang penting dalam pelaksanaan Reformasi Birokrasi kaitannya dengan penyelenggaraan tugas pemerintahan, pembangunan dan pelayanan.

2. Sarana efektif untuk mengarahkan seluruh pimpinan di jajaran pemerintahan agar dapat meningkatkan disiplin dalam menerapkan prinsip Good Governance dan fungsi manajemen modern secara taat asas.

3. Sarana terbaik untuk mengarahkan pengelolaan dana serta sumber daya lainnya agar berjalan secara efektif dan efisien untuk meningkatkan kinerja penyelenggaraan pemerintahan, pembangunan dan pelayanan publik secara terukur dan berkelanjutan.

4. Sarana untuk mengetahui serta mengukur tingkat keberhasilan/kegagalan setiap pimpinan di jajaran Pemerintahan Republik Indonesia dalam melaksanakan Misi, Target, serta Tujuan Strategis sebagaimana telah ditetapkan di dalam Rencana Strategis dan Rencana Kerja Tahunan.

5. Sarana untuk mendorong usaha dalam rangka untuk penyempurnaan suatu organisasi, kebijakan publik, dan sistem perencanaan serta penganggaran, ketatalaksanaan, metode kerja serta prosedur pelayanan kepada masyarakat, tahapan pelaporan dan mencegah terjadinya praktik-praktik KKN. 
6. Sarana untuk mendorong kreativitas, produktivitas, sensitivitas, disiplin serta tanggung jawab para karyawan di lingkungan Pemerintahan Republik Indonesia untuk melaksanakan tugas/jabatan sesuai dengan aturan/kebijakan, prosedur dan tata kerja yang sudah ditetapkan.

Tujuan SAKIP berdasarkan pedoman SAKIP Kepmendag Nomor 794/2015 diatas, untuk mengetahui efektivitas Sistem Akuntabilitas Kinerja Instansi Pemerintah Dinas Pertanian dan pangan Kota Magelang ditinjau berdasarkan pelaksanaan yang telah dilaksanakan pada dinas tersebut, yaitu :

1. Pelaksanaan Reformasi Birokrasi di Dinas Pertanian dan Pangan seluruhnya sudah berjalan dengan baik. Adanya penerapan SAKIP ini dapat mendorong pelaksanaan tata birokrasi sehingga dapat lebih baik jika dibandingkan dengan sebelumnnya. Dengan melaksanakan SAKIP di Dinas pertanian dan Pangan secara tidak langsung memaksa pegawai untuk lebih disiplin terhadap pekerjaan serta melakukan pekerjaan sesuai dengan aturan yang berlaku.

2. Dinas Pertanian dan Pangan Kota Magelang menerapkan sistem absensi secara fingerprint. Dengan adanya sistem fingerprint diharapkan bisa meningkatan disiplin karyawan.

3. Adanya perbedaan kesesuaian antara bidang keahlian pegawai dengan penempatan bidang kerja seperti misalnya lulusan pertanian ditempatkan pada bagian keuangan dan perencanaan. Namun dengan menerapkan SAKIP Dinas Pertanian dan Pangan Kota Magelang berusaha untuk memperbaiki SDM agar karyawan dapat bekerja secara profesional sesuai dengan pekerjaannya dan dalam pelaksanaan tugas serta fungsi dapat dilaksanakan dengan baik.

4. Dengan penerapan SAKIP setiap akhir tahun diadakan pelaporan terkait dengan pertanggung jawaban akuntabilitas kinerja yang disebut dengan LAKIP. Sama halnya di Dinas Pertanian dan Pangan Kota Magelang ini juga membuat laporan pertanggung jawaban akuntabilitas kinerja selama 1 tahun. Dengan adanya LAKIP ini berfungsi untuk mengukur 
seberapa tingkat keberhasilan kinerja dan kegagalan dari instansi dalam pelaksanaan dari Misi, Tujuan, serta Sasaran Strategis sebagaimana yang sebelumnya ditetapkan pada Rencana Strategis dan Rencana Kerja Tahunan.

5. Dengan adanya SAKIP berguna untuk selalu berusaha mendorong penyempurnaan organisasi, kebijakan, sistem perencanaan dan penganggaran, ketatalaksanaan, metode kerja untuk melakukan perbaikan setiap tahunnya agar selalu mengalami peningkatan .

6. Dengan adanya SAKIP di Dinas Pertanian dan Pangan Kota Magelang mendorong kreativitas pegawai, produktivitas, sensitivitas, disiplin kerja serta tanggung jawab atau kewajiban para pegawai dalam melaksanakan tugas dan jabatannya harus selalu mematuhi dan menaati segala peraturan yang berlaku.

Penerapan SAKIP di Dinas Pertanian dan Pangan Kota Magelang, sebagian besar tujuan dari penerapan SAKIP sudah berjalan sesuai dengan tujuannya. Namun sampai sekarang masih belum adanya kesadaran dari masyarakat mengenai Akuntabilitas Kinerja Instansi Pemerintah yang beranggapan bahwa instansi pemerintah belum akuntabel, padahal dalam kenyataanya setiap instansi pemerintah telah melakukan pelaporan pada setiap tahunnya. Berdasarkan hasil wawancara yang telah dilakukan oleh peneliti terhadap narasumber yaitu Soleh Widodo selaku Kepala Bagian Program dan Keuangan, terdapat faktor penghambat dan pendukung efektifitas di Dinas Pertanian dan Pangan Kota Magelang.

Faktor penghambat efektifitas di Dinas Pertanian dan Pangan Kota Magelang antara lain:

1. Jaringan internet yang terkadang tidak stabil sehingga memperlambat pekerjaan pegawai.

2. Belum adanya fasilitas Genset didalam kantor, sehingga ketika pemadaman listrik pegawai tidak dapat melaksanakan tugasnya. 
Faktor-faktor pendukung yang mempengaruhi efektivitas Sistem Akuntabilitas Kinerja Instansi Pemerintah (SAKIP) Dinas Pertanian dan Pangan Kota Magelang adalah :

1. Adanya SOP

2. Adanya SDM yang memadai

3. Fasilitas yang sudah memadai dalam proses pelaksanaan kegiatan operasional

4. Dukungan APBN dan APBD

Penjelasan faktor pendukung dan penghambat tersebut terdapat penelitian yang relevan dalam mendukung penelitian ini. (Yusrianti \& Safitri, 2015) mengemukakan bahwa kendala-kendala yang dihadapi dalam implementasi SAKIP di tingkat SKPD antara lain : lemahnya fungsi monitoring dalam implementasi SAKIP pada Kota palembang, terbatasnya alokasi anggaran dalam menyusun laporan kinerja instansi, komitmen pimpinan instansi masih kurang mengenai pelaksanaan SAKIP, kualitas SDM masih rendah, dan lemahnya koordinasi antar bidang di masing-masing SKPD. Penelitian lain yaitu (Raharja et al., 2018) mengemukakan beberapa atribut yang menjadi kelemahan dalam penerapan SAKIP di Kota Bogor yaitu kesesuaian antar dokumen perencanaan, perencanaan kinerja yang berorientasikan pada hasil, kesesuaian program atau pelaksanaan kegiatan dengan renstra, penyusunan indikator kinerja individu, pengukuran kinerja serta pemanfaatan pengukuran kinerja.

\section{KESIMPULAN}

Berdasarkan hasil penelitian disimpulkan bahwa efektivitas dari pelaksanaan SAKIP di Dinas Pertanian dan Pangan Kota Magelang setiap tahun mengalami peningkatan, dilihat pada tingkat keberhasilan program kerja yang telah dilaksanakan. Namun, masih terdapat kendala seperti kurangnya kesadaran dari masyarakat mengenai Akuntabilitas Kinerja Instansi Pemerintah yang memandang bahwa instansi pemerintah belum akuntabel. 
Faktor penghambat efektifitas di Dinas Pertanian dan Pangan Kota Magelang yaitu Jaringan internet yang terkadang tidak stabil sehingga memperlambat pekerjaan pegawai, Belum adanya fasilitas Genset didalam kantor sehingga ketika pemadaman listrik pegawai tidak dapat melaksanakan tugasnya.

Faktor-faktor pendukung yang mempengaruhi efektivitas Sistem Akuntabilitas Kinerja Instansi Pemerintah (SAKIP) Dinas Pertanian dan Pangan Kota Magelang adalah : Adanya SOP, Adanya SDM yang memadai, Fasilitas yang sudah memadai dalam proses pelaksanaan kegiatan operasional, Dukungan APBN dan APBD.

\section{DAFTAR RUJUKAN}

Andriani, W., Rosita, I., \& Ihsan, H. (2015). Penerapan Sistem Akuntabilitas Kinerja Instansi Pemerintah ( SAKIP ) Dalam Mewujudkan Good Governance Pada Politeknik Negeri Padang. Jurnal Akuntansi \& Manajemen, 10, 51-60.

Handayaningrat. (1995). efektifitas. 16.

Enditya, Lukman, \& Faroby, A. (2018). Atribut Dalam Penerapan SAKIP.

Hennink et al. (2012). penelitian kualitatif.

Laporan Kinerja Instansi Pemerintah (LKJiP) Dinas Pertanian dan Pangan Kota Magelang. (2018).

Mardiasmo. (2004). akuntabilitas publik. 20.

Mardiasmo. (2008). akuntansi sektor publik.

Modul BPKP Edisi kelima. (2007). Akuntabilitas Instansi Pemerintah.

Pedoman SAKIP LAN. (2010).

Peraturan daerah Kota Magelang Nomor 3 Tahun 2016 tentang Pembentukan dan Susunan Perangkat Daerah.

Peraturan Presiden Nomor 29 Tahun 2014 Tentang Sistem Akuntabilitas Kinerja Instansi Pemerintah.

Peraturan Presiden Republik indonesia Nomor 29 Tahun 2014 tentang Sistem Akuntabilitas Kinerja Instansi Pemerintah.

Permenpan RB No. 29 Tahun 2010.

Permenpan RB Nomor 53 Tahun 2014 tentang Petunjuk Teknis Perjanjian Kinerja, Pelaporan Kinerja, dan Tata cara Reviu atas Laporan Kinerja Instansi Pemerintah.

Perpres No. 29 Tahun 2014.

Puspasari, E. (2015). EFEKTIVITAS SISTEM AKUNTABILITAS KINERJA INSTANSI PEMERINTAH ( SAKIP ) DINAS KEPENDUDUKAN DANPENCATATAN SIPIL. 1-

Ricky Mukaromah - Efektivitas Sistem Akuntabilitas Kinerja Instansi Pemerintah (SAKIP) $\quad$ Page | 98 pada Dinas Pertanian dan Pangan Kota Magelang 
16.

Raharja, E. L., Baga, L. M., \& Falatehan, A. F. (2018). STRATEGI PENINGKATAN AKUNTABILITAS KINERJA INSTANSI PEMERINTAH KOTA BOGOR. Jurnal Manajemen Pembangunan Daerah, 10(2).

UU Nomor 5 Tahun 2014 tentang Kinerja sebagai dasar pemberian tunjangan dan pengembangan kompensasi.

Wikipedia. (2019). Kota Magelang. https://id.wikipedia.org/wiki/Kota_Magelang Yusrianti, H., \& Safitri, R. (2015). IMPLEMENTASI SISTEM AKUNTABILITAS KINERJA INSTANSI PEMERINTAH (SAKIP) PADA SATUAN KERJA PERANGKAT DAERAH (SKPD) DI LINGKUNGAN PEMERINTAH KOTA PALEMBANG. Jurnal Manajemen \& Bisnis Sriwijaya, 13. 